\title{
步党 \\ VENI, CREATOR SPIRITUS E O MOVIMENTO DE RENOVAÇÃO CARISMÁTICA CATÓLICA: ESTRATÉGIAS ESPACIAIS DE DIFUSÃO DA FÉ NA PÓS-MODERNIDADE.
}

- JEFFERSON RODRIGUES DE OLIVEIRA ${ }^{1}$

RESUMO: O PRESENTE ARTIGO TEM POR OBJETIVO DESTACAR A IMPORTÂNCIA DE UM MOVIMENTO CRESCENTE NA IGREJA CATÓLICA APOSTÓLICA ROMANA DENOMINADO RENOVAÇÃO CARISMÁTICA CATÓLICA. ESTE MOVIMENTO PROGRESSIVO É FORTEMENTE MARCADO E DELIMITADO POR PRÁTICAS DEVOCIONAIS DO CATOLICISMO LIGADO A TERCEIRA PESSOA DA SANTÍSSIMA TRINDADE - O ESPÍRITO SANTO. COMO MOVIMENTO, A RCC É MARCADA PELA PRÁTICA DOS FLUXOS NA IDA AOS DIFERENTES LUGARES DE ORAÇÃO A PARTIR DE DIFERENTES ESCALAS PARA A MANIFESTAÇÃO DA FÉ DO HOMEM RELIGIOSO NO SEU INDIVIDUAL PARA O COLETIVO (OLIVEIRA, 2015). BUSCANDO ATENDER O OBJETIVO PROPOSTO PARA ESTE ARTIGO, NOSSA ABORDAGEM GEOGRÁFICA SERÁ DIVIDIA EM DUAS PARTES, ENFATIZANDO A EXPERIÊNCIA DA FÉ. SÃO ELAS: A) RENOVAÇÃO DA FÉ NA IGREJA CATÓLICA APOSTÓLICA ROMANA: NOVAS COMUNIDADES E; B) UM NOVO PENTECOSTES: A RENOVAÇÃO CARISMÁTICA CATÓLICA.

PALVRAS-CHAVE: GEOGRAFIA CULTURAL, GEOGRAFIA E RELIGIÃo, RENOVAÇÃO CARISMÁTICA CATÓLICA, RCC, DIFUSÃO. 
A religião como um fenômeno cultural e uma prática social vem servindo até os dias atuais como fonte de estudos e pesquisas para diversas ciências dedicadas ao estudo do homem. Dentre essas ciências, podemos destacar a antropologia, a sociologia, a filosofia, a história, entre outras. Em nosso trabalho, destacaremos a visão geográfica deste fenômeno.

Considerado pela literatura como um dos movimentos mais atuantes na atual conjuntura da Igreja Católica Apostólica Romana, o movimento de Renovação Carismática Católica - RCC, é delimitado por práticas devocionais do catolicismo ligado a terceira pessoa da Santíssima Trindade - o Espírito Santo, a partir de seus dons e carismas. Como movimento, a RCC é marcada pela prática dos fluxos na ida aos diferentes lugares de oração a partir de diferentes escalas para a manifestação da fé do homem religioso no seu individual para o coletivo (OLIVEIRA, 2015). Essa característica peculiar do ser religioso em sua prática individual para o coletivo a partir de sua transcendência ocorre em grupos de oração, nas missas, em acampamentos de oração, aprofundamentos, formações doutrinárias do movimento, assim como, em estudos atuais a partir do ciberespaço e dos meios de comunicação (OLIVEIRA, 2014).

A Renovação Carismática Católica é um movimento em que podemos destacar uma dualidade a partir de pesquisas acadêmicas, ou em dados oriundos de estudos do próprio movimento na literatura teológica e no senso comum. A primeira visão destaca o movimento como estratégia política de evangelização e difusão da fé católica para minimizar a evasão de fiéis da Igreja; a segunda visão, no senso comum e no campo teológico, a RCC é interpretada como um movimento que teve sua gênese no final da década de 60 nos Estados Unidos da América, e é voltado para a Igreja Católica Apostólica Romana como uma renovação espiritual e um contato mais expressivo com o Espírito Santo.

A partir desta lógica dual, o objetivo deste artigo é destacar o estudo geográfico do movimento de Renovação Carismática Católica na Igreja Católica Apostólica Romana, sua gênese, seu processo de difusão espacial, suas principais características e importância estratégica na atual conjuntura de uma sociedade em constantes transformações de valores e crenças.

Visando atender o objetivo proposto para este artigo, nossa abordagem geográfica será dividia em duas partes, enfatizando a experiência da fé. São elas: a) Renovação da fé na Igreja Católica Apostólica Romana: novas comunidades e; b) Um Novo Pentecostes: a Renovação Carismática Católica. 
Renovação da fé na Igreja Católica

Apostólica

Romana:

novas

comunidades

Os estudiosos da religião abordam a vivência religiosa do homem e as tendências ora de secularização, ora de recrudescimento religioso das sociedades contemporâneas. Alguns intelectuais demonstram a existência da religião cívica em algumas sociedades, assim como uma queda na formação de profissionais especializados no trabalho religioso (ROSENDAHL, 2001).

Corroborando com as ideias de Rosendahl (1999), o senso de santidade acaba sendo levado a um lugar secundário na sociedade, o que favorece perdas ao sagrado, ou seja, um desencanto do sagrado e o abandono de práticas religiosas. O homem torna-se cada vez mais independente da religião e de suas práticas, se centrando em suas experiências reais ou seu cotidiano, o dia-a-dia.

A partir do final da década de 1960, esse movimento de laicidade, ou seja, um processo de secularização, uma forma de autocompreensão do social, fundamentada em ideologias ou visões de mundo produzidas por outras esferas ou instituições - o Estado, a ciência, o mercado, os meios de comunicação de massa se tornaram mais frequentes. Estamos diante de uma vivência cultural globalizada de sacralidade, isto é, pessoas, objetos e lugares reconhecidos como sagrado. Isso representa a liberdade do homem frente à religião social e sua submissão à religiosidade cívica e pseudoreligiões (ROSENDAHL, 2001). Podemos aqui ainda acrescentar, a partir dessas novas transformações na sociedade, no século XXI, um período pós-moderno ou hipermoderno (LIPOVETSKY e SERROY, 2011), um século bem tecnológico e com uma individualidade social crescente.

Peter Berger (1985), em estudos de sociedades, pós-60 acreditava que essa laicidade da sociedade iria continuar perdurando por um longo período de tempo e poderia ocorrer até mesmo um possível esfriamento religioso do homem na sociedade. Apesar, porém, de visualizarmos uma mudança cultural no mundo pós-70, observamos um recrudescimento da fé. Isto é, há pessoas que buscam na religião, o contato com o sagrado, algo que transcende seu cotidiano, ou seja, o extra-cotidiano.

Com o recrudescimento da fé, notavelmente no final dos anos 60 , década estas de inúmeras manifestações culturas e sociais, a religião católica acompanha as mudanças. Lança novos movimentos eclesiais, nova dinâmica na prática e na vivência religiosa do devoto. $\mathrm{O}$ destaque dessa mudança é o movimento das comunidades eclesiais ligadas ao movimento da Renovação Carismática RCC, que surgiu no ano de 1967, pósConcílio Vaticano II que reordenou as bases da Igreja Católica frente às indagações que a sociedade da época desejava. 
Nesta perspectiva, surgiram comunidades, estas de vida e aliança, de pessoas que largavam tudo, familiares e pertences, em busca da evangelização. Aqui no Brasil podemos destacar como grandes difusoras desse processo de Renovação Carismática Católica as comunidades Canção Nova e Shalom, consideradas as duas maiores ligadas a esse movimento no Brasil.

As comunidades inseridas no seio da renovação, como assim podem destacar, tem por objetivo trazer à sociedade atual um novo modelo de vivência social, tanto na política, na família, na arte, na economia, tendo por finalidade a geração de uma nova cristandade em um novo milênio. $\mathrm{O}$ aporte teórico nas ciências sociais acerca desse processo de renovação na Igreja Católica tem demonstrado, a partir de uma literatura vasta, o real interesse de se aprofundar mais academicamente nesse movimento, suas práticas, suas ações e transformações que a cada novo dia vem modificando de maneira visível as bases da Igreja Católica no Brasil e no Mundo.

Autores como Benedetti (2009), Camurça (2009), Carranza (2009, 2011), Carranza e Mariz (2009), Gabriel (2008, 2009, 2010), Oliveira (2009), Oliveira (2010, 2011), Oliveira e Rosendahl (2014), Pereira (2008, 2009) entre outros nos trazem enriquecedores estudos acerca dessa linha de evangelização da Igreja Católica Apostólica Romana, a RCC.
A Renovação Carismática como movimento religioso é alicerçada a partir de um maior contato com a terceira pessoa da Santíssima Trindade - o Espírito Santo, seus dons e carismas. Os Católicos que iniciam sua participação nesse movimento passam, a partir do batismo do Espírito Santo, a possuir novas práticas e uma vivência de fé totalmente diferenciada de um católico de cunho tradicional (OLIVEIRA, 2011, 2015; PEREIRA, 2008, 2009). A prática do católico carismático muitas vezes é confundida com as práticas Pentecostais ou Neopentecostais.

Para muitos, a Renovação Carismática é um movimento renovador na Igreja, porém o seu principal objetivo é possibilitar uma (re)catolização dos católicos, tornando-os mais cientes de sua fé e suas práticas, além de trazer novamente o tradicionalismo para a Igreja, com uma nova roupagem e linguajar. A partir desta estratégia, seria possível tornar os católicos mais praticantes, agregariam novos fiéis, além de diminuir a evasão de católicos para outras doutrinas religiosas.

Os novos movimentos eclesiais que surgiram na Igreja Católica Apostólica Romana, em especial a RCC, fomentam para a Igreja, uma oportunidade de criar estratégias, para manutenção do controle político-econômico-religioso em seus territórios religiosos. Esse controle deve ocorrer em suas diferentes esferas, seja ela física - mundo real, ou virtual, a partir da internet e dos meios de comunicação. 
seus principais antecedentes, assim como o seu processo de difusão e abrangência. A

[...] o catolicismo carismático brasileiro é uma forma composta de evangelização para quem já é católico. É um catolicismo voltado somente para dentro do próprio catolicismo. Em outras palavras, está em jogo uma forma de evangelização cujo objetivo é "recatolicizar" os católicos [...] (GABRIEL, 2008, p. 84)

A renovação, além de ser um movimento forte e crescente na Igreja Católica, possui duas frentes de difusão muito fortes: a primeira seria através de uma difusão por contato, ou seja, as vivências em igrejas, grupos de oração, encontros, entre outros; o segundo processo é a evangelização católica através dos meios de comunicação (CARRANZA, 2009，2011; OLIVEIRA，2011，2015; OLIVEIRA e ROSENDAHL, 2014). A Igreja Católica atualmente observa uma real necessidade de se inserir em diversos meios para poder assegurar sua hegemonia. Todas essas transformações atuais são oriundas do Concílio Vaticano II.

No item a seguir, faremos um breve histórico do que seria esse movimento renovador - conservador na Igreja Católica,
Renovação Carismática Católica como movimento é dotado de uma espacialidade marcante e repleta de simbolismos e significados.

\section{Um Novo Pentecostes: a Renovação Carismática Católica}

Fé e Devoção ao sagrado atributos de essência religiosa - são individuais e únicos e, dessa maneira, a princípio, invisíveis aos olhos. Todavia, em determinados contextos ritualísticos no espaço e no tempo, podem ser percebidos materialmente. Ao estudarmos a teologia da Renovação Carismática Católica, é possível observar uma espacialidade fortemente marcada pela prática de fluxos: os agentes que moram e frequentam a localidade, e por fixos: formas espaciais religiosas criadas para atender a demanda dos fiéis.

Esse movimento eclesial católico apresenta identidade própria e difere de outros movimentos católicos como os cursilhos, os movimentos dos focolares, a teologia da libertação, as novas evangelizações, entre outros. Pautado no reavivamento dos carismas e da efusão do Espírito Santo - Novo Pentecostes - a exemplo do que aconteceu na primeira festa de Pentecostes, quando Jesus Cristo derramou sobre todos os seus apóstolos, inclusive Maria, o batismo no Espírito Santo, através de seus dons e carismas, é o movimento que, atualmente, mais se 
expande no Brasil e no mundo (SILVA, 2007).

O movimento da Renovação Carismática, surgido no ano de 1967 nos Estados Unidos da América, é herdeiro do movimento pentecostal apostólico que marcou a fundação da Igreja (SILVA, 2007). Os movimentos eclesiais se organizam e se articulam dentro da Igreja Católica de acordo com uma vocação específica que os distinguem. Devido à diversidade de dados, a literatura afirma que a vocação da Renovação Carismática é cantar, pregar, orar por curas e milagres, entre outros. Vale mencionar o pensamento de Silva (2007, p. 63) acerca da vocação da Renovação Carismática Católica, apresentada como estratégia evangelizadora e nova prática da fé católica.

Esta reflexão nos esclarece a renovação como uma estratégia evangelizadora, ação nova da prática da fé católica. Ao reconhecer como renovadora, é necessário saber o que está na ação de renovar. Sendo assim, traremos uma breve análise sobre o primeiro Pentecostes da Igreja Primitiva, pois para compreendermos a renovação espiritual carismática é preciso saber os primeiros tempos da Igreja. No quadro a seguir, temos um breve resumo relacionado ao primeiro Pentecostes na Igreja Católica Apostólica Romana.

Ao observarmos o quadro 1, percebemos que, antes que viesse a ocorrer na Igreja o chamado derramamento do Espírito Santo, ocorreram processos narrados na bíblia que precederam ao que iria se realizar. Para Silva (2007), antes que todos os acontecimentos viessem a ocorrer, Deus prepararia o seu povo, para que suas promessas se cumprissem, ou seja, uma preparação para tudo aquilo que seria realizado no dia de Pentecostes, promessas estas prescritas em profecias. A realização para o cumprimento das promessas ocorreu na passagem de Atos 2, 1-18 (BÍBLIA, 2004). 
Quadro 1 - Pentecostes.

\begin{tabular}{|c|}
\hline Primeiro Pentecostes \\
\hline Antecedente Bíblico - Moisés - Números 11, 1-30 \\
\hline $\begin{array}{l}\text { Promessas de Deus - através de profecias - Ez 11, } 19 \text {; } \\
\text { Ez 36, 24-27; Ez 37, 9-10; Jl 3,1; Mt 3, 11b; Mc 1, 8; Lc 3, } \\
\text { 16; Jo 1,33; Lc 11,13; 24,29; Jo 3, 5-8; Zc 14, 8; Is 58, 11; } \\
\text { Jo 3, 37-39; Jo 14, 16; 16, 13-14; At 1,8 }\end{array}$ \\
\hline $\begin{array}{l}\text { Cumprimento das Promessas - Atos 2, 1-18 - } \\
\text { Derramamento do Espírito Santo-O Paráclito. }\end{array}$ \\
\hline $\begin{array}{c}\text { Pentecostes } \\
\text { Nascimento da Igreja Católica Pentecostal }\end{array}$ \\
\hline
\end{tabular}

Fonte: Autor, 2014, baseado em SILVA (2007).

Para o movimento da Renovação Carismática Católica, a passagem de Atos 2, 1-18, possui um grande simbolismo, sendo está a chave para o florescimento da renovação no seio da Igreja, uma vez que a partir dela, observaríamos o nascimento de uma Igreja Pentecostal.

O tempo e o espaço são conceitos que nos iluminam ao retratar os movimentos religiosos que ocorrem em diferentes lugares e épocas. Como nosso objeto de estudo recai no movimento renovador, passemos então, agora, ao seu processo atual.
Para legitimidade de um fenômeno espiritual (SILVA, 2007) ser considerado um Novo Pentecostes, deveria ocorrer a repetição nos dias atuais, das ocorrências do primeiro, o que Jesus concedeu sobre os primeiros discípulos. Desta maneira, para entendermos o nascimento da Renovação Carismática Católica - RCC - temos que tomar por base os mesmos acontecimentos que legitimaram o primeiro Pentecostes na Igreja Católica, para isto elaboramos o Quadro 2 que contém os elementos deste novo processo. 


\begin{tabular}{|l|}
\hline \multicolumn{2}{|c|}{ Novo Pentecostes - RCC } \\
\hline $\begin{array}{l}\text { Antecedente Bíblico - Atos 2, 1-18 - Derramamento } \\
\text { do Espírito Santo - O Paráclito. }\end{array}$ \\
\hline $\begin{array}{l}\text { Promessas de Deus - Oração e ação da freira Elena } \\
\text { Guerra; Moções do Espírito Santo em Leão XIII; } \\
\text { Moções do Espírito Santo em João XXIII. }\end{array}$ \\
\hline $\begin{array}{l}\text { Cumprimento das Promessas - Ação do Espírito } \\
\text { Santo no Concílio Vaticano II }\end{array}$ \\
\hline Novo Pentecostes - 1967 \\
Nascimento da Renovação Carismática Católica \\
\hline
\end{tabular}

Fonte: Autor, 2014, baseado em SILVA (2007).

A partir dos processos históricos mencionados nas passagens bíblicas, como foram analisados no quadro 1, observamos uma mudança no lócus do ministério profético. Antes do primeiro Pentecostes, Deus escolhia as pessoas para o exercício deste ministério. Com o advento do Pentecostes Apostólico, porém, o mesmo ministério era derramado naqueles que aceitavam a Cristo, quando eram batizados no Espírito Santo, pelo qual, a partir desse batismo, viriam os demais carismas.

Durante um período, após o Pentecostes Apostólico, assim como todo o ensejo da Igreja por um novo batismo, após um período de abundância, os mesmos sinais antes presenciados ficaram durante muito tempo decrescidos por motivos ainda desconhecidos (SILVA, 2007). Ou seja, observou-se um esfriamento desses carismas, dos dons carismáticos, devendo ressaltar que, apesar do rareamento das manifestações pentecostais, estas não deixaram de existir.

A partir dessa perspectiva, trazemos como base um novo período de tempo como fizemos anteriormente com o primeiro Pentecostes, para adentrarmos nos processos que viriam a gerar o Novo Pentecostes e, como consequência, a RCC.

Como base para a busca de um Novo Pentecostes na Igreja, tomava-se como referência a palavra de Atos 2,1 - 41 (BÍBLIA, 2004), acreditando que tudo aquilo que havia ocorrido nesta passagem bíblica viria ocorrer novamente, através de um novo batismo no Espírito Santo, por meio de uma efusão do Espírito.

Assim como a Igreja primitiva teve uma preparação para o dia de Pentecostes, desde épocas remotas no antigo testamento através de Moisés, até os 
apóstolos, a partir de toda uma sequência, de um antecedente bíblico, das promessas e seus cumprimentos, o mesmo ocorreu para um Novo Pentecostes.

Durante esse período de preparação, Jesus também suscitou pessoas como verdadeiros profetas, de maneira que, a partir do século XIX, o Espírito Santo incitou a Igreja no sentido de ensejar um Novo Pentecostes, um movimento de (re)novar um religare entre o homem e o Espírito.

Para tanto, o Espírito Santo, a partir destas incitações, levantou novos personagens centrais para aquilo que, em 1967, seria conhecido como um Novo Pentecostes e o surgimento da Renovação Carismática Católica. Dentre eles, respectivamente podemos citar a Freira Elena Guerra, que na literatura é considerada por muitos autores como a mediadora entre o Espírito Santo e o Papa Leão XIII.

A partir de inspirações e visualizações, a freira escreveu 12 cartas ao Papa Leão XIII, que, a partir do recebimento das primeiras, entre os anos de 1895 e 1903, publicou um documento, o Provida Matris Caritate, por meio do qual pedia para que a Igreja viesse, entre as festas da Ascensão e do Pentecostes, celebrar uma novena ao Espírito Santo. Logo após, visando ainda um maior contato com o Espírito Santo, publicou uma Encíclica chamada Divinum Illud Munus, que seria uma preparação para o século XX.
Em 1901, atendendo aos apelos do Espírito Santo, O qual o tinha por intermédio da irmã Elena Guerra, invocouO pessoalmente, cantando o hino Veni, Creator Spiritus (Vinde, Espírito Criador) onde, segundo Silva (2007, p. 67), "vemos neste gesto do santo Pontífice, uma consagração do Século $\mathrm{XX}$ ao Espírito Santo.".

Ainda segundo Silva (2007, p. $67)$,

O Espírito Santo, em seus mistérios, não se faz esperar. A este respeito é interessante notar que no mesmo dia da oração do Papa, por volta das 23 horas, numa cidade estadunidense chamada Topeka, localizada no Estado de Kansas, enquanto um grupo protestante orava, liderado pelo Reverendo Charles Fox Parham, que se dedicava a estudar o batismo no Espírito Santo, começaram as atuais manifestações de efusão do Espírito Santo, quando uma jovem de nome Agnes Ozman orou em línguas. Logo outras pessoas também começaram a orar, 
incluindo o Reverendo

Parham. Este fato acontecido em Topeka é o marco do Pentecostalismo moderno.

Outro coadjuvante para a formulação desse grande evento, foi o Papa Leão XXIII. A partir de sua experiência, em uma viagem a uma aldeia da então Tchecoslováquia, ainda bispo, Ângelo Roncalli via que a totalidade da população vivia em permanente graça de Pentecostes, como narrado na Primeira Carta aos Coríntios, observando muitas vezes os carismas ali ocorridos, de maneira que sentiu um desejo inflamado por Jesus desejando esta mesma graça para toda a Igreja. Como Papa, João XXIII, convocou um concílio ecumênico, o segundo realizado em Roma, no qual realizou uma oração preparatória com aquilo que o Senhor colocava em seu íntimo em preparação para o concílio.

Renova os teus milagres nestes nossos dias, como em um novo Pentecostes. Permite que tua Igreja, unida em pensamento e firme em oração com Maria, a Mãe de Jesus, e guiada pelo abençoado Pedro, possa prosseguir na construção do reino do nosso Divino Salvador, reino de verdade e de justiça, reino do amor e da paz. Amém. (SILVA, 2007, p. 68)

No que tange ao cumprimento das promessas para um novo Pentecostes, este foi marcado a partir do Concílio Vaticano II (1962-1965), no qual teve uma importância ímpar, sendo o precursor para o nascimento da Renovação Carismática Católica.

Considerado um dos mais importantes concílios da Igreja Católica, o Concílio Vaticano II (FERREIRA, 2011) mudou de maneira significativa a organização e a estrutura da Igreja em determinados segmentos e ritos. No que se refere à Renovação, ou ao Pentecostalismo na Igreja, Silva (2007, p. 68) nos traz que esse concílio foi uma profecia singular.

Os novos caminhos do Espírito Santo para a Igreja Católica, que começaram nos tempos da Irmã Elena Guerra e do Papa Leão XIII, atingiram no concílio uma delineação nítida, que mais justo seria dizer que a partir dos documentos conciliares nele gerados, $\mathrm{o}$ Movimento Pentecostal tem imensas rodovias bem pavimentadas, largas avenidas com sinalização 
bem ordenada e visível, por onde pode progredir com segurança.

Nesse ínterim, assim como os profetas do antigo testamento foram escolhidos por Deus, desde o antecedente bíblico até o cumprimento das promessas em Pentecostes, o mesmo ocorreu para o Novo Pentecostalismo Católico daqueles escolhidos por Jesus e citados anteriormente, como a Irmã Elena Guerra, o Papa Leão XIII, o Papa João XXIII, assim como os padres conciliares que participaram do Concílio Vaticano II, para uma legitimação - o novo Pentecostes Católico - para a Igreja atual.

Enquanto a RCC como movimento eclesial na Igreja ainda não se iniciara, o Espírito Santo encontrou no Cursilho de Cristandade um ambiente propício para a sua efusão (SILVA, 2007). No ano de 1965, ocorreu a efusão do Espírito Santo em reuniões, com manifestação de oração em línguas - a glossolalia, ou seja, o ato de falar línguas estranhas (PEREIRA, 2009). Os Cursilhos forneceram aquelas pessoas que seriam considerados os primeiros líderes da RCC.

O ano de 1967 ficou conhecido como o marco principal de surgimento da Renovação Carismática Católica. O movimento veio a surgir durante um retiro de estudantes da Universidade do Espírito Santo de Duquesne, Pensilvânia - Estados Unidos da América. Após essas informações fornecidas na literatura específica do Movimento Carismático, é oportuno situá-las no contexto da época em que ocorreram.

$\mathrm{Na}$ literatura, observamos que, nos anos 60, surgiram movimentos de protestos sociopolítico-cultural e religioso em várias partes do mundo. Foram os anos de 1968 e 1969 marcados por momentos de crise no comportamento da sociedade mundial: na música, no vestuário, no movimento feminista, dentre outros. A religião acompanhou essas mudanças e tentou ser flexível ao momento de crise. A geógrafa Zeny Rosendahl (2012) apresenta uma justificativa contextualizada com as ideias weberianas de que, nos momentos de guerra e de crise socioeconômica, a religião tende a ser um refúgio para o homem. Em algumas sociedades, ocorre um recrudescimento religioso do grupo social envolvido.

O parágrafo anterior nos remete a um período vivenciado em nossa sociedade, que também propiciou uma mudança nas bases da Igreja Católica Apostólica Romana através do Concílio Vaticano II (OLIVEIRA, 2010, 2015; OLIVEIRA e ROSENDAHL, 2014). Esse Concílio possibilitou o surgimento de um dos movimentos que mais crescem na Igreja Católica atualmente, a Renovação Carismática Católica-RCC.

A cada período histórico, a sociedade humana passa por inúmeras mudanças e transformações, tanto na 
política, na cultura como no âmbito social e na economia, entre outras esferas da sociedade. A religião como um fenômeno cultural (OLIVEIRA, 2010, 2011; OLIVEIRA e ROSENDAHL, 2014) também vem se modificando e acompanhando essas novas mudanças da sociedade.

De acordo com Ranaghan (1972, p. 11) no que tanto o Concílio Vaticano II,

[...] com sua ênfase no desenvolvimento de uma personalidade cristã vital, vemos a regulação do jejum dar lugar à responsabilidade pessoal, as atitudes barrocas e medievais na missa e nos sacramentos se dobrarem à experimentação e à adaptação relevante, de maneira comunitária cultuar. A Igreja declara que deve servir ao mundo e ao povo que nele existe.

Segundo Silva (2007, p. 68),

A partir dos acontecimentos de Duquesne, o Espírito Santo, literalmente, arrastou uma multidão de católicos para o atual pentecostalismo, porém desta vez sem que saíssem da Igreja. Em pouco tempo a Renovação já existia em todos os continentes.

Como todo movimento inicial, a RCC encontrou barreiras para seu processo de difusão e, neste primeiro momento, uma barreira de cunho político, que veio ocorrer principalmente pela não-aceitação de algumas lideranças católicas e protestantes, que não aceitavam o pentecostalismo na Igreja. Segundo essas lideranças, as pessoas que experimentavam desse novo batismo, católicos ou protestantes, poderiam vir a perder seus vínculos com suas antigas denominações.

De acordo com Barbosa (2000, p. 13), a Renovação Carismática Católica,

[...] é sem dúvida, o grande sopro do Espírito Santo para o mundo moderno. Nunca o mundo precisou tanto de pessoas que pudessem traduzir em sua vida, em sua oração e em seu testemunho a presença real e visível de Deus. E é por isso que o Espírito Santo, que conduz a história da Igreja desde o seu primeiro instante, agora está soprando de um jeito 
novo, de modo a levar cada um de nós a uma profunda e radical experiência de Deus. Em tempo algum o ser humano esteve tão longe de Deus como está agora. $\mathrm{E}$ isto, especialmente nos países que se dizem católicos.

O recrudescimento religioso pode ser analisado por vários de seus comportamentos em diferentes práticas religiosas. No caso da Renovação Carismática Católica segundo Barbosa (2000, p. 10-11)

Em 1971, começava-se a falar em Renovação Carismática Católica no Brasil. As relações foram as mais diversas possíveis. Muitos julgavam se tratar de uma nova seita, uma nova religião. Para outros, trata-se de uma ação do governo norte-americano para combater a Igreja que estava surgindo da base as Comunidades Eclesiais de Base e a Teologia da Libertação, essa última emergindo também nessa mesma época. (Barbosa, 2000, p. 10-11).

A partir de Barbosa (2000), observamos que a Renovação Carismática se insere no Brasil, a partir da década de 1970, sendo, desta maneira, interpretada de diferentes maneiras, menos naquilo que seria o seu foco principal, um novo derramamento espiritual para a Igreja Católica. Na literatura, encontramos alguns autores que ressaltam que o movimento de renovação na Igreja Católica Apostólica Romana é mais uma investida da Igreja, visando minimizar a saída de fiéis para outras religiões, doutrinas ou seitas.

No que tange ao alcance espacial da Renovação Carismática Católica, esta se encontra presente em 235 países, chegando à marca de quase 150 mil grupos de oração. $\mathrm{O}$ maior número deles se encontra no Brasil, México e Filipinas. A Renovação tem como principal objetivo renovar a Igreja, reconquistar e trazer de volta os católicos que se encontravam afastados do exercício religioso. Como movimento dentro da Igreja, ela possui uma estrutura organizada e hierarquizada, formada por conselhos e coordenações, tendo um escritório internacional na cidade de Ann Arbor, em Michigan, EUA, reconhecido e aprovado pelo Vaticano (ICCRS, 2012).

$\mathrm{Na}$ figura 1 , temos o processo de difusão da Renovação Carismática Católica pelo mundo, dividido pelos sete continentes. Ele divide o crescimento da RCC em três períodos de tempo, a saber: 
1970 - ano da difusão inicial da RCC, surgida em 1967; o ano de 1980 e a data final do levantamento tendo por base o ano 2000. Se analisarmos estas informações contidas no mapa, podemos observar a expressividade que o movimento adquiriu em quantidade de adeptos na América Latina - quadro 3. Ao visualizarmos o quadro 4, observamos que praticamente metade dos católicos carismáticos existentes atualmente no mundo, com base no ano 2000, estão localizados na América Latina.
Segundo Volcan (2003), a população de católicos carismáticos no mundo totaliza uma quantidade de aproximadamente 120 milhões de católicos, totalizando em torno de $11,3 \%$ do total de católicos batizados. Vale ressaltar que essas informações têm por base o ano de 2000, e até o presente momento observamos um crescimento ainda significativo deste movimento renovador, o que poderá implicar em uma porcentagem bem maior em futuros levantamentos. 
Figura 1 - Crescimento da RCC nos sete continentes.

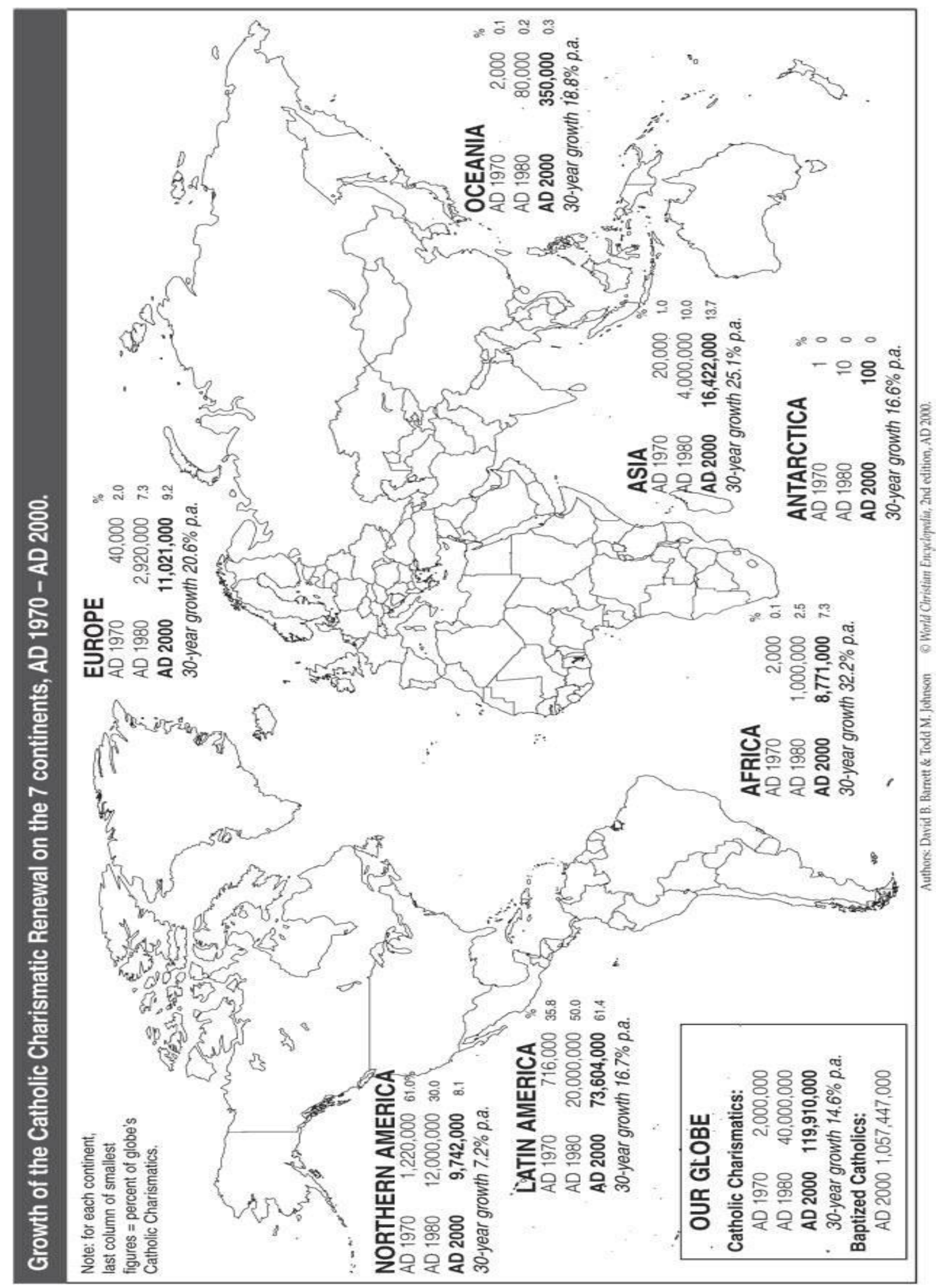

Fonte: ICCRS, 2012. 
Quadro 3 - Crescimento da RCC na América Latina.

\begin{tabular}{|c|c|c|}
\hline \multicolumn{2}{|c|}{ Crescimento da Renovação Carismática Católica na América Latina } \\
$\mathbf{1 9 7 0}-\mathbf{2 0 0 0}$
\end{tabular}

Fonte: Autor, 2014, baseado em ICCRS (2012).

Quadro 4 - Crescimento da RCC no Mundo.

\begin{tabular}{|c|c|}
\hline \multicolumn{2}{|c|}{ Crescimento da Renovação Carismática Católica no Mundo } \\
$\mathbf{1 9 7 0}-\mathbf{2 0 0 0}$
\end{tabular}

Fonte: Autor, 2014, baseado em ICCRS (2012). 


\section{Considerações finais}

Chegamos, neste momento, ao final desse trabalho, que teve por objetivo a partir dos estudos geográficos da religião, estudar um movimento crescente na Igreja Católica Apostólica Romana, denominado Renovação Carismática Católica - RCC. A partir do artigo, torna-se claro que esse movimento renovador surgido em 1967 pós-Concílio Vaticano II, além de eclesial, está servindo de suporte estratégico da fé católica, para (re)catequizar, manter e assim evitar a evasão/perda de fiéis para outras doutrinas e religiões.

Ao longo do texto, fora possível tornar inteligíveis as transformações pelas quais nossa sociedade vem perpassando ao longo dos anos, e principalmente nas últimas décadas até sua atual condição no chamado mundo pós-moderno ou hipermoderno (LIPOVETSKY e SERROY, 2011). Frente a essas novas transformações, a Igreja não poderia ficar de fora, devendo, assim, criar estratégias de difusão para que haja uma continuidade da hierarquia atual e o controle.

\footnotetext{
Nota

1 Doutorando em Geografia pelo Programa de Pósgraduação em Geografia - PPGEO/UERJ / Professor pesquisador e colaborador no NEPEC/PEAGERC/UERJ. Email: jeffersongeouerj@yahoo.com.br.
}

Referencias Bibliográficas

BARBOSA, Sandy R. C de J. "A Territorialidade do Movimento de Renovação Carismática Católica na Paróquia Nossa Senhora de Copacabana, RJ'. Monografia de conclusão do curso de Pós-Graduação em Políticas Territoriais do Estado do Rio de Janeiro - UERJ - 2000.
Destacamos ao longo do texto que o movimento de Renovação Carismática Católica se caracteriza na diferenciação da busca do novo, ao mesmo, favorecendo um retorno da tradicionalidade da Igreja. Vale ressaltar que essa tradicionalidade está ligada a um novo e diferente vigor, abraçado principalmente pelos jovens que questionam às congregações tradicionais a sua capacidade de atrair devotos.

Vale ressaltar que o tema não se esgota, havendo ainda inúmeras outras frentes de estudos acerca deste movimento para ser pesquisado e aprofundado. $\mathrm{O}$ presente texto servirá de exemplo para um maior entendimento deste movimento, sua dinâmica, sua difusão e principalmente suas ações estratégicas na política, na economia e no social, assim como, nos meios de comunicação.

Finalizo destacando que, a partir deste movimento, as peregrinações e as práticas religiosas locais são vivenciadas de maneiras distintas. Configura-se um novo católico. O processo de pós-modernidade recai no trazer o tradicional com uma nova dinâmica e configurações modernas (OLIVEIRA, 2011, 2015).

BENEDETTI, Luiz Roberto. Novos rumos do catolicismo. In: CARRANZA, Brenda; MARIZ, Cecília e CAMURÇA, Marcelo. (Org.) Novas comunidades católicas: em busca do espaço pós-moderno. Aparecida, SP: Idéias \& Letras, 2009, p. 17-32.

BERGER, Peter. L. O Dossel Sagrado: Elementos para uma Teoria Sociológica da Religião. São Paulo: Paulus, 1985. (Coleção Sociologia e Religião).

BÍBLIA Sagrada. $160^{\circ}$ ed. São Paulo: Ave-Maria, 2004.

CAMURÇA, Marcelo Ayres. Tradicionalismo e meios de comunicação de massa: o catolicismo midiático. In: CARRANZA, Brenda; MARIZ, Cecília e CAMURÇA, Marcelo. (Org.) Novas comunidades católicas: em busca do 
espaço pós-moderno. Aparecida, SP: Ideias \& Letras, 2009, p. $59-77$.

CARRANZA, Brenda. Perspectivas da neopentecostalização católica. In: CARRANZA, Brenda; MARIZ, Cecília e CAMURÇA, Marcelo. (Org.) Novas comunidades católicas: em busca do espaço pós-moderno. Aparecida, SP: Ideias \& Letras, 2009, p. 33-58

CARRANZA, Brenda e MARIZ, Cecília Loreto. Novas comunidades católicas: por que crescem? In: CARRANZA, Brenda; MARIZ, Cecília e CAMURÇA, Marcelo. (Org.) Novas comunidades católicas: em busca do espaço pósmoderno. Aparecida, SP: Ideias \& Letras, 2009, p. 139-170.

CARRANZA, Brenda. Catolicismo Midiático. Aparecida, SP: Ideias \& Letras, 2011.

CORREAA, Roberto. L. Espaço: um conceito- chave da Geografia. In: CASTRO, I. E.; GOMES, P. C. C.; CORREA, R. L. (Org.) Geografia: Conceitos e Temas. 11.ed. Rio de Janeiro: Bertrand Brasil, 2008.

ELIADE, Mircea. O Sagrado e o Profano: a essência das religiões. Tradução Rogério Fernandes. $2^{\circ}$. ed. São Paulo: Martins Fontes, 2008.

FERREIRA, Pe. Wagner. A formação da Consciência Moral nas Novas Comunidades. São Paulo: Editora Canção Nova, 2011

GABRIEL, Eduardo. In: CARRANZA, Brenda; MARIZ, Cecília e CAMURÇA, Marcelo. (Org.) Novas comunidades católicas: em busca do espaço pós-moderno. Aparecida, SP: Ideias \& Letras, 2009, p. 139-170.

GABRIEL, Eduardo. Expansão da renovação carismática católica brasileira: a chegada da canção nova em FátimaPortugal. In: Teorías Y Prácticas Emergentes en Antropología de la Religion, 2008, p.77-94. Disponível em: <http://www.ankulegi.org/wp-

content/uploads/2012/03/1005Gabriel.pdff> Acesso em: 01 set. 2014.

GOMES, Paulo C. C. Cenários para a Geografia: sobre a espacialidade das imagens e suas significações. In: CORREAA, R. L e ROSENDAHL, Z. (Org). Espaço e Cultura: Pluralidade Temática. Rio de Janeiro: EdUERJ, 2008. pp. 187-209.

INTERNATIONAL Catholic Charismastic Renewal Services (ICCRS). Site internacional da Renovação Carismática Católica. Disponível em: 〈www.iccrs.org/> Acesso em: 05 fev. 2012.

LIPOVETSKY, G. e SERROY, J. A cultura mundo, resposta a uma sociedade desorientada. Tradução: Maria Lúcia Machado. São Paulo: Companhia das Letras, 2011;

NORTON, William. Cultural geography: themes, concepts, analyses. Oxford University Press, 2000.

OLIVEIRA, Eliane Martins de. A "Vida no Espírito" e o dom de ser "Canção Nova". In: CARRANZA, Brenda; MARIZ, Cecília e CAMURÇA, Marcelo. (Org.) Novas comunidades católicas: em busca do espaço pós-moderno. Aparecida, SP: Ideias \& Letras, 2009, p. 195-221.

OLIVEIRA, Jefferson R. de. Hierópolis Carismática em Cachoeira Paulista: Canção Nova e as peregrinações pósmodernas. Espaço e Cultura, $n^{\circ} 28$. Dezembro de 2010. Rio de Janeiro: NEPEC/UERJ: 71-92;
OLIVEIRA, Jefferson R. de. Representações e práticas religiosas da Renovação Carismática Católica em Cachoeira Paulista: o exemplo da Canção Nova. Espaço e Cultura (UERJ), v. 30, p. 36-54, 2011. Disponível em: <http://www.epublicacoes.uerj.br/index.php/espacoecultura/ article/view/4951>

OLIVEIRA, Jefferson R. de. Canção Nova e as Peregrinações Pós-Modernas: Hierópolis Carismática de Cachoeira Paulista. São Paulo: Paco Editorial, 2015.

OLIVEIRA, Jefferson R de; ROSENDAHL, Zeny. Religião, Politica e Espaço: a difusão da fé através do Mass Media e as Online Communities. In: MOREIRA, Alberto da [et al.]. Religião, espetáculo e intimidade: múltiplos olhares. Goiânia: Ed. da PUC Goiás, 2014.

PARK, Chris. Religion and geography. In: Hinnells, J. (ed.) Routledge Companion to the Study of Religion. London: Routledge, p.1-29, 2004.

PEREIRA, Edilson S. O Espírito da Comunidade: Passagens entre o mundo e o sagrado na Canção Nova. Dissertação Mestrado em Sociologia e Antropologia. PPGSA, IFCSUFRJ. Rio de Janeiro, 2008.

PEREIRA, Edilson S. O ESPÍRITO DA ORAÇÃO OU COMO CARISMÁTICOS ENTRAM EM CONTATO COM DEUS. Religião \& Sociedade (Impresso), v. 29, p. 5881,2009

RANAGHAN, Kevin e Dorothy. Católicos Pentecostais. Rio de Janeiro, Alínea. 1972.

ROSENDAHL, Zeny. Porto das Caixas. Espaço Sagrado da Baixada Fluminense. São Paulo. Departamento de Geografia, USP. Tese de Doutorado, 1994.

ROSENDAHL, Zeny. O Espaco, o Sagrado e o Profano. In: ROSENDAHL, Z. e CORRỄA, R. L. Manifestações da cultura no espaço. Rio de Janeiro: EdUERJ, 1999.

ROSENDAHL, Zeny. Espaço, Política e Religião. In: ROSENDAHL, Z. e CORRÊA, R. L (org.), Religião, Identidade e Território, Rio de Janeiro: EdUERJ, 2001.

ROSENDAHL, Zeny. Espaço e Religião: uma abordagem geográfica. $2^{\circ}$ ed. Rio de Janeiro: EdUERJ, 2002.

ROSENDAHL, Zeny. Espaço, Cultura e Religião: Dimensões de Análise. In: ROSENDAHL, Z. e CORRÊA, R. L (org.), Introdução à Geografia Cultural, Rio de Janeiro: Bertrand Brasil, 2003.

ROSENDAHL, Zeny. Hierópolis e Procissões: o sagrado e o espaço. In: Religião \& Cultura: Espaço Sagrado e Religiosidade. PUC/SP. ${ }^{\circ} 14$ (julho./dez. 2008). São Paulo: Paulinas-Educ, 2008

ROSENDAHL, Zeny. Primeiro a Obrigação, Depois a Devoção: estratégias da Igreja Católica no Brasil, de 1500 a 2005. Rio de Janeiro: EdUERJ, 2012;

SANTOS, Milton. A natureza do Espaço - técnica e tempo, razão e emoção. $4^{\circ}$ ed. São Paulo: EDUSP, 2006.

SILVA, Dercides P. da. Renovação Carismática Católica Brasil - A Identidade da Renovação Carismática Católica. São Paulo: Loyola, 2007.

VOLCAN, Marcos Dione Ugoski. Renovação Carismática Católica: uma leitura teológica e pastoral. Dissertação de Mestrado, Pontifícia Universidade Católica do Rio Grande do Sul, 2003. 
VENI, CREATOR SPIRITUS AND THE CATHOLIC CHARISMATIC RENEWAL MOVEMENT: SPATIAL STRATEGIES DIFFUSION OF FAITH IN POST-MODERN.

\begin{abstract}
THIS ARTICLE AIMS TO HIGHLIGHT THE IMPORTANCE OF A GROWING MOVEMENT IN THE ROMAN CATHOLIC CHURCH CALLED CATHOLIC CHARISMATIC RENEWAL - CCR. THIS PROGRESSIVE MOVEMENT IS STRONGLY MARKED AND DELIMITED BY DEVOTIONAL PRACTICES OF CATHOLICISM ON THE THIRD PERSON OF THE TRINITY - THE HOLY SPIRIT. AS A MOVEMENT, THE CCR IS CHARACTERIZED BY THE PRACTICE OF FLOWS ON THE WAY TO THE DIFFERENT PLACES OF PRAYER FROM DIFFERENT SCALES FOR THE MANIFESTATION OF THE RELIGIOUS MAN FAITH IN HIS INDIVIDUAL TO THE COLLECTIVE (OLIVEIRA, 2015). SEEKING TO MEET THE PROPOSED OBJECTIVE FOR THIS ARTICLE, OUR GEOGRAPHIC APPROACH WILL BE DIVIDED INTO TWO PARTS, EMPHASIZING THE EXPERIENCE OF FAITH. THEY ARE: A) RENEWAL OF FAITH IN THE ROMAN CATHOLIC CHURCH: NEW COMMUNITIES AND; B) A NEW PENTECOST: THE CATHOLIC CHARISMATIC RENEWAL.
\end{abstract}

KEYWORDS: CULTURAL GEOGRAPHY, GEOGRAPHY AND RELIGION, CATHOLIC CHARISMATIC RENEWAL, CCR, DIFUSION. 